Dhaka Univ. J. Biol. Sci. 21(1): 29-38, 2012 (January)

\title{
BACTERIAL ABUNDANCE IN INDIAN WHITE SHRIMP, PENAEUS INDICUS COLLECTED FROM TWO DIFFERENT MARKET CONDITIONS OF DHAKA CITY
}

\author{
Saima Sharif Nilla, Md. Ghulam Mustafa*, Dewan Ali Ahsan, \\ Md. Mahmudur Rahman KHAN and Md. Anisur RaHman KHAN ${ }^{1}$ \\ Department of Fisheries, University of Dhaka, Dhaka-1000, Bangladesh
}

Key words: Bacterial abundance, Frozen food, Penaeus indicus, Food borne disease

\begin{abstract}
A study was accomplished in regard to the microbiological abundance in the muscle of Indian White Shrimp (Penaeus indicus) collected from three departmental chain shops and three local markets of Dhaka metropolitan city has been assessed in terms of total bacterial count (TBC), coliform and SalmonellaShigella (SS) counts. The TBC ranged from $2.1 \pm 0.20 \times 10^{4}$ to $4.7 \pm 0.50 \times 10^{5} \mathrm{cfu} / \mathrm{g}$ for departmental shop frozen shrimp and $4.2 \pm 0.45 \times 10^{6}$ to $1.3 \pm 0.50 \times 10^{8} \mathrm{cfu} / \mathrm{g}$ for local market iced shrimp. The total coliform count ranged between $1.6 \pm 0.20 \times$ $10^{2}$ and $2.1 \pm 0.25 \times 10^{3} \mathrm{cfu} / \mathrm{g}$ for the chain shop frozen shrimp and $2.8 \pm 0.30 \times 10^{3}$ and $7.8 \pm 0.50 \times 10^{5} \mathrm{cfu} / \mathrm{g}$ for the retail market iced shrimp. Furthermore, the Salmonella-Shigella (SS) count for chain shop frozen and local market iced shrimp varied from $0.5 \pm 0.0 \times 10^{2}$ to $1.3 \pm 0.10 \times 10^{2} \mathrm{cfu} / \mathrm{g}$ and $0.7 \pm 0.0 \times 10^{2}$ to $2.1 \pm 0.25 \times$ $10^{2} \mathrm{cfu} / \mathrm{g}$, respectively. Presence of Vibrio spp. was confirmed in 11 samples (5 from departmental shops and 6 from local markets). In case of antibiotic sensitivity pattern of the indicator and pathogenic isolates, all of them were resistant to penicillin and bacitracin. Most of the isolates were sensitive to streptomycin, chloramphenicol and kanamycin. The results confirmed that the samples of local markets contained high pathogenic bacterial load which are supposed to be threat to food safety creating food borne diseases.
\end{abstract}

\section{Introduction}

Food borne microbiological hazards causing infections and illnesses are closely related to food safety concerning with animal proteins derived from fish, fishery products, meats and meat products. This creates a burning question for all consumers with a high risk commodity with regard to pathogenic bacterial contaminations alarming to food safety challenge. Food borne diseases result from ingestion of bacteria, toxins and cells produced by microorganisms present in food. The intensity of the signs and symptoms may vary with the amount of contaminated food ingested and susceptibility of the individuals to the toxin ${ }^{(1)}$.

*Corresponding author. < mgmustafabd@yahoo.com>.

${ }^{1}$ Department of Microbiology, University of Dhaka, Dhaka-1000, Bangladesh. 
The FAO and WHO of the United Nation(2) report that illness due to contaminated food is the most widespread health problem in the contemporary world and an important cause of reduced economic productivity ${ }^{(3)}$. Biological contaminants constitute the major cause of food borne diseases ranging from mild indisposition to chronic or life threatening illness ${ }^{(4)}$. Therefore, for the assurance of consumers European Commission Health and Consumer Protection Directorate General (EC/DG), United States Food and Drug Administration (USFDA) and Canadian Food Inspection Agency (CFIA) legally mandated in 1999 that the hazard analysis critical control point (HACCP) system and complementary Standard Sanitation Operation Procedures (SSOPs) be implemented for processing all purchased seafood products(2).

The quality of the processed products largely depends on the quality of raw materials and it is difficult to preserve the freshness of raw materials when there is a long period of time between the harvesting and processing. During this period, shrimps and fishes continue to be deteriorated due to improper handling and further processing can never bring back its freshness. Low quality frozen foods are related with improper processing and poor hygienic conditions. Consequently, frozen shrimps and fishes may be contaminated with different types of bacteria such as Vibrio, Salmonella, coliform, faecal coliform, streptococci and Staphylococcus spoiling the frozen fishes are responsible for causing cholera and other food borne diseases ${ }^{(5)}$. It is well documented that raw or frozen shrimp and fishes provide important epidemiological pathways for food borne disease transmission(6). Due to the presence of different types of bacteria in frozen shrimps and fishes, they may lose their exportability. Quality of export frozen shrimps and fishes is of major concern to fish processors and public health authorities.

This study was undertaken to determine the microbiological status of frozen shrimps in departmental shops and iced shrimp of local markets of Dhaka city with a view to providing potential approaches for food safety with regards to food borne diseases.

\section{Materials and Methods}

Shrimp samples were collected from three different departmental chain shops and three local retail markets at Dhaka city in between April, 2010 and December, 2010. A total of 24 samples where 4 - 5 shrimps were taken in each sample, 12 from departmental chain shops and 12 from local markets were collected to assess the bacterial load. Identification was made according to Shafi( ${ }^{(7)}$. The shrimp samples were collected in special sterile Ziploc bags to avoid further contamination and transported in an insulated box with ice to maintain the temperature $\left(4-6^{\circ} \mathrm{C}\right)$ and stored at $-20^{\circ} \mathrm{C}$ at the laboratory until use ${ }^{(8)}$. Samples were processed and used within $24 \mathrm{hrs}$ of collection.

The samples were thawed at room temperature for $5-6 \mathrm{hrs}$ to melt the ice and were taken to the safety cabinet to peel off the shell remaining the head. The edible part body was taken and made small pieces using sterile scissors. Shrimp (25 g) sample was 
weighed carefully and accurately by using a weighing scale and dissolved in $225 \mathrm{ml}$ of $0.85 \% \mathrm{NaCl}$ solution in a stomacher bag. Each sample was then stomached for $60 \mathrm{sec}$ separately. Stomacher treated samples $(0.1 \mathrm{ml})$ was then poured or spread plated in the microbiological medium.

The microbiological analysis was performed as per the standard methods adopted from Online Bacteriological Analytical Manual, USFDA for detection, enumeration and identification of individual organisms ${ }^{(9)}$.

Total bacterial count (TBC) was obtained directly on nutrient agar (Becton Dickinson, France). The colonies were incubated at $35-37^{\circ} \mathrm{C}$ for $24 \mathrm{hrs}$ and expressed in cfu/g. Nutrient agar was used without saline water because it allows only salt tolerant bacteria to grow.

Dilutions made for TBC were pour-plated on MacConkey agar (Oxoid Ltd., Hampshire, England); typical pink colonies were counted after $24 \mathrm{~h}$ of incubation at 35 $37^{\circ} \mathrm{C}$. The suspected isolates were streaked on $\mathrm{mFC}$ agar plates and incubated at $44.5^{\circ} \mathrm{C}$ for $24 \mathrm{hrs}$. Typical blue colonies were counted and was further confirmed by growing in eosin methylene blue (EMB) agar plates (Oxoid Ltd., Hampshire, England).

The sample ( $25 \mathrm{~g}$ ) was homogenized in saline water. After the samples were enriched a loopful of growth from the broth was streaked on Salmonella-Shigella agar (SSA; Oxoid), typical black colonies from plates were isolated and identified by biochemical tests.

Xylose lysine deoxycholate (XLD) agar was also used for the selective isolation of Shigella and Salmonella spp. After appropriate serial dilutions, the samples were pourplated on XLD agar (Oxoid Ltd., Hampshire, England). Typical pink and translucent colonies with or without rough edges were picked up after $48 \mathrm{hrs}$ of incubation at 35 $37^{\circ} \mathrm{C}$ and confirmed by biochemical tests.

The sample ( $25 \mathrm{~g}$ ) was homogenized in $225 \mathrm{ml}$ of alkaline peptone water (APW) and incubated at $35^{\circ} \mathrm{C}$ for $24 \mathrm{hrs}$. After appropriate serial dilutions, the homogenates were pour-plated on TCBS agar (Oxoid Ltd., Hampshire, England). Different $\mathrm{NaCl}$ concentrations $(3,5,10$ and $15 \%)$ were used to confirm growth of the suspected different types of Vibrio isolates for biochemical tests.

Dilutions made for TBC were spread-plated on mannitol salt agar (MSA) (Oxoid Ltd., Hampshire, England). Typical yellow colonies were counted after 48 hrs of incubation at $35^{\circ} \mathrm{C}$.

Biochemical tests were done according to the manual for general bacteriology of the American Society of Microbiology ${ }^{(10)}$. Biochemical tests done were as follows: Oxidase test, catalase test, carbohydrate fermentation/utilization test, Kligler's iron agar (KIA) test, indole production test, methyl red (MR) test, Voges-Proscauer (VP) test, citrate 
utilization test, nitrate reduction test, motility indole urea (MIU) test, and salt tolerance $(3,5,10$ and $15 \% \mathrm{NaCl})$ test were performed to identify the bacteria of interest ${ }^{(11)}$.

Susceptibility of E. coli, Salmonella, Shigella, Vibrio and Staphylococcus isolates to different antimicrobial agents was measured in vitro according to Kirby-Bauer methods ${ }^{(12)}$. Commercially available 12 antimicrobial discs [ampicillin (AMP), amoxicillin (AML) bacitracin (B), chloramphenicol (C), ciprofloxacin (CIP), erythromycin (E), gentamycin $(\mathrm{GN})$, penicillin $\mathrm{G}(\mathrm{PG})$, streptomycin $(\mathrm{S})$, tetracycline $(\mathrm{TE})$, penicillin $(\mathrm{P})$ and kanamycin (K)] were used for the test. The E. coli, Salmonella-Shigella, and Staphylococcus isolates were used against the antibiotics.

Statistical analysis was performed with the SPSS software package (Verson 11.5, SAS Institute Inc., Cary, USA). Tukey's HSD post hoc for the multiple comparisons was followed with the level of significance to present the data as mean \pm SEM.

\section{Results and Discussion}

Tables 1 and 2 show the individual results of microbiological analysis conducted on collected 24 frozen and fresh shrimp samples from different departmental chain shops and different local markets. The results show that bacterial count was always higher in each sample of local markets.

The TBC of most of the samples were found high and cross the limit $\left(10^{5} \mathrm{cfu} / \mathrm{g}\right)$ given by International Commission on Microbiological Specifications for Foods ${ }^{(13)}$. The highest load (Table 2) was found in sample $19\left(1.3 \pm 0.50 \times 10^{8}\right)$ and the lowest load (Table 1) was in sample $5\left(2.1 \pm 0.20 \times 10^{4}\right)$. In respect of bacterial load, quality of shrimp of departmental shop was better than local markets; this might due to the contamination from the source of water, poor hygiene and sanitation condition of the processing premises $^{(14)}$. Catching vessels also act as source of contamination of harmful microorganisms ${ }^{(15)}$. As a result many microbes begin to multiply before freezing. But freezing only can limit the growth of microbes for a short period. When favorable condition comes back, most of the microbes can multiply within short time ${ }^{(16)}$.

Total coliform was present in all samples in high quantity and exceeded the limit $\left(10^{2}\right.$ $\mathrm{cfu} / \mathrm{g}$ ) of ICMSF ${ }^{(13)}$. The highest load was $7.8 \pm 0.50 \times 10^{5} \mathrm{cfu} / \mathrm{g}$ in sample 21 and the lowest load was $1.6 \pm 0.20 \times 10^{2} \mathrm{cfu} / \mathrm{g}$ in sample 6 as shown in Tables 2 and 1, respectively. The presence of total coliform indicates that the samples were contaminated during handling, processing and selling including holding temperature. Moreover, the contamination may also come from water used for washing or icing(17).

Because the origin of faecal coliform are more specific than that of the total coliform group of bacteria, faecal coliform is considered a more accurate indication of animal or human waste than the total coliform ${ }^{(18)}$. The highest total faecal coliform count was $2.3 \pm$ $0.25 \times 10^{4} \mathrm{cfu} / \mathrm{g}$ in sample 15 whereas the lowest was $1.1 \pm 0.15 \times 10^{2} \mathrm{cfu} / \mathrm{g}$ in sample 24 . Besides the highest load of E. coli was $3.1 \pm 0.25 \times 10^{3} \mathrm{cfu} / \mathrm{g}$ and the lowest was $0.4 \pm 0.50 \times$ 
$10^{2} \mathrm{cfu} / \mathrm{g}$ found in samples 9 and 17, respectively (Tables 1 and 2). This result indicates that the water or processing units are somehow contaminated. Despite the water cannot be linked directly to the contamination by human sewage, since the bacteria are found in high concentration within sewage. However, Japan, USA and other European countries do not allow the presence of $E$. coli in the shrimp or shrimp food ${ }^{(19)}$.

Table 1. Numbers (Mean \pm SEM) of total bacteria, total coliform, faecal coliform and E. coli detected in different shrimp samples from departmental chain shops.

\begin{tabular}{lcccc}
\hline \multirow{2}{*}{$\begin{array}{c}\text { Sample } \\
\text { No. }\end{array}$} & TBC & TC & FC & EC \\
\cline { 2 - 5 } & $4.5 \pm 0.45 \times 10^{4}$ & $1.5 \pm 0.20 \times 10^{3}$ & $5.0 \pm 0.45 \times 10^{2}$ & $2.3 \pm 0.15 \times 10^{3}$ \\
2 & $3.7 \pm 0.30 \times 10^{4}$ & $2.0 \pm 0.25 \times 10^{3}$ & $3.7 \pm 0.35 \times 10^{2}$ & $2.5 \pm 0.20 \times 10^{2}$ \\
3 & $5.1 \pm 0.50 \times 10^{5}$ & $2.0 \pm 0.25 \times 10^{3}$ & $2.5 \pm 0.30 \times 10^{3}$ & $2.6 \pm 0.20 \times 10^{3}$ \\
4 & $4.5 \pm 0.45 \times 10^{5}$ & $2.2 \pm 0.25 \times 10^{2}$ & $1.9 \pm 0.20 \times 10^{2}$ & $2.9 \pm 0.25 \times 10^{3}$ \\
5 & $2.1 \pm 0.20 \times 10^{4}$ & $1.9 \pm 0.25 \times 10^{3}$ & $4.0 \pm 0.40 \times 10^{2}$ & $2.8 \pm 0.15 \times 10^{3}$ \\
6 & $3.5 \pm 0.35 \times 10^{5}$ & $1.6 \pm 0.20 \times 10^{2}$ & $1.7 \pm 0.20 \times 10^{2}$ & $1.3 \pm 0.10 \times 10^{3}$ \\
7 & $4.7 \pm 0.50 \times 10^{5}$ & $1.9 \pm 0.25 \times 10^{3}$ & $3.9 \pm 0.40 \times 10^{2}$ & $0.7 \pm 0.00 \times 10^{2}$ \\
8 & $3.5 \pm 0.35 \times 10^{5}$ & $1.6 \pm 0.20 \times 10^{3}$ & $5.2 \pm 0.45 \times 10^{2}$ & $0.6 \pm 0.10 \times 10^{2}$ \\
9 & $4.1 \pm 0.40 \times 10^{5}$ & $2.0 \pm 0.25 \times 10^{3}$ & $1.9 \pm 0.20 \times 10^{3}$ & $3.1 \pm 0.25 \times 10^{3}$ \\
10 & $2.9 \pm 0.30 \times 10^{5}$ & $1.8 \pm 0.25 \times 10^{3}$ & $2.4 \pm 0.25 \times 10^{2}$ & $2.1 \pm 0.15 \times 10^{3}$ \\
11 & $2.4 \pm 0.25 \times 10^{5}$ & $2.1 \pm 0.25 \times 10^{3}$ & $2.8 \pm 0.30 \times 10^{2}$ & $2.0 \pm 0.15 \times 10^{3}$ \\
12 & $2.8 \pm 0.30 \times 10^{5}$ & $1.4 \pm 0.20 \times 10^{3}$ & $1.4 \pm 0.20 \times 10^{2}$ & $1.9 \pm 0.10 \times 10^{2}$ \\
\hline
\end{tabular}

Table 2. Numbers (Mean \pm SEM) of total bacteria, total coliform, faecal coliform and E. coli detected in different shrimp samples from local fish market.

\begin{tabular}{lcccc}
\hline Sample & \multicolumn{4}{c}{ Bacterial load (cfu/g) } \\
\cline { 2 - 5 } No. & TBC & TC & FC & EC \\
\hline 13 & $2.8 \pm 0.30 \times 10^{7}$ & $3.9 \pm 0.40 \times 10^{5}$ & $2.1 \pm 0.20 \times 10^{4}$ & $1.5 \pm 0.20 \times 10^{2}$ \\
14 & $2.6 \pm 0.25 \times 10^{7}$ & $6.9 \pm 0.50 \times 10^{5}$ & $1.6 \pm 0.15 \times 10^{4}$ & $1.8 \pm 0.20 \times 10^{2}$ \\
15 & $3.3 \pm 0.35 \times 10^{7}$ & $5.7 \pm 0.60 \times 10^{5}$ & $2.3 \pm 0.25 \times 10^{4}$ & $0.6 \pm 0.50 \times 10^{2}$ \\
16 & $4.8 \pm 0.50 \times 10^{6}$ & $3.2 \pm 0.35 \times 10^{4}$ & $1.9 \pm 0.20 \times 10^{3}$ & $0.8 \pm 0.50 \times 10^{2}$ \\
17 & $4.2 \pm 0.45 \times 10^{6}$ & $2.8 \pm 0.30 \times 10^{3}$ & $1.0 \pm 0.10 \times 10^{2}$ & $0.4 \pm 0.50 \times 10^{2}$ \\
18 & $5.3 \pm 0.25 \times 10^{6}$ & $4.8 \pm 0.40 \times 10^{4}$ & $1.6 \pm 0.15 \times 10^{2}$ & $0.9 \pm 0.15 \times 10^{2}$ \\
19 & $1.3 \pm 0.50 \times 10^{8}$ & $4.8 \pm 0.45 \times 10^{5}$ & $1.2 \pm 0.10 \times 10^{4}$ & $1.2 \pm 0.15 \times 10^{3}$ \\
20 & $9.8 \pm 0.25 \times 10^{7}$ & $6.3 \pm 0.50 \times 10^{5}$ & $1.4 \pm 0.15 \times 10^{3}$ & $0.7 \pm 0.50 \times 10^{2}$ \\
21 & $1.1 \pm 0.25 \times 10^{8}$ & $7.8 \pm 0.50 \times 10^{5}$ & $1.9 \pm 0.20 \times 10^{4}$ & $1.1 \pm 0.15 \times 10^{3}$ \\
22 & $5.8 \pm 0.45 \times 10^{7}$ & $3.2 \pm 0.25 \times 10^{3}$ & $1.5 \pm 0.15 \times 10^{3}$ & $0.9 \pm 0.15 \times 10^{2}$ \\
23 & $4.3 \pm 0.45 \times 10^{7}$ & $4.8 \pm 0.45 \times 10^{3}$ & $2.9 \pm 0.30 \times 10^{3}$ & $1.9 \pm 0.20 \times 10^{3}$ \\
24 & $5.1 \pm 0.50 \times 10^{7}$ & $1.8 \pm 0.20 \times 10^{4}$ & $1.1 \pm 0.15 \times 10^{3}$ & $0.5 \pm 0.50 \times 10^{2}$ \\
\hline
\end{tabular}


Since, according to $\operatorname{ICMSF}^{(13)}$, all the shrimp samples were exceeding the limit $1.0 \times$ $10^{2} \mathrm{cfu} / \mathrm{g}$, further identification was carried out to investigate the presence of other harmful and pathogenic microorganisms such as Salmonella spp., Shigella spp., Vibrio spp. and Staphylococcus spp. The Salmonella-Shigella (SS) count ranged from $0.5 \pm 0.0 \times 10^{2}$ to $2.1 \pm 0.25 \times 10^{2} \mathrm{cfu} / \mathrm{g}$ for the shrimps also exceed the limit $1.0 \times 10^{2} \mathrm{cfu} / \mathrm{g}$ (Table 3). The

Table 3. Abundance (mean \pm SEM) of Salmonella-Shigella, Vibrio spp. and Staphylococcus spp. in different shrimp samples.

\begin{tabular}{lccc}
\hline Sample & \multicolumn{3}{c}{ Bacterial load (cfu/g) } \\
\cline { 2 - 4 } No. & $\mathrm{SS}$ & Vibrio spp. & Staphylococcus spp. \\
\hline 1 & $1.2 \pm 0.20 \times 10^{2}$ & $1.9 \pm 0.20 \times 10^{3}$ & $9.0 \pm 0.25 \times 10^{2}$ \\
2 & $\mathrm{NF}^{\mathrm{a}}$ & $1.6 \pm 0.20 \times 10^{3}$ & $7.5 \pm 0.25 \times 10^{2}$ \\
3 & $\mathrm{NF}$ & $\mathrm{NF}$ & $2.1 \pm 0.25 \times 10^{2}$ \\
4 & $1.1 \pm 0.20 \times 10^{2}$ & $2.1 \pm 0.0 \times 10^{2}$ & $2.8 \pm 0.30 \times 10^{3}$ \\
5 & $\mathrm{NF}$ & $1.6 \pm 0.0 \times 10^{2}$ & $3.3 \pm 0.30 \times 10^{3}$ \\
6 & $\mathrm{NF}$ & $\mathrm{NF}$ & $2.3 \pm 0.30 \times 10^{3}$ \\
7 & $0.5 \pm 0.0 \times 10^{2}$ & $\mathrm{NF}$ & $5.1 \pm 0.35 \times 10^{3}$ \\
8 & $\mathrm{NF}$ & $0.9 \pm 0.0 \times 10^{2}$ & $7.1 \pm 0.40 \times 10^{3}$ \\
9 & $1.3 \pm 0.10 \times 10^{2}$ & $\mathrm{NF}$ & $4.7 \pm 0.35 \times 10^{3}$ \\
10 & $1.1 \pm 0.10 \times 10^{2}$ & $\mathrm{NF}$ & $4.1 \pm 0.30 \times 10^{4}$ \\
11 & $\mathrm{NF}$ & $\mathrm{NF}$ & $4.6 \pm 0.20 \times 10^{2}$ \\
12 & $0.6 \pm 0.0 \times 10^{2}$ & $\mathrm{NF}$ & $5.0 \pm 0.20 \times 10^{2}$ \\
13 & $1.0 \pm 0.10 \times 10^{2}$ & $1.5 \pm 0.0 \times 10^{2}$ & $6.2 \pm 0.40 \times 10^{3}$ \\
14 & $\mathrm{NF}$ & $\mathrm{NF}$ & $2.1 \pm 0.25 \times 10^{3}$ \\
15 & $1.9 \pm 0.25 \times 10^{2}$ & $\mathrm{NF}$ & $3.1 \pm 0.25 \times 10^{3}$ \\
16 & $\mathrm{NF}$ & $\mathrm{NF}$ & $4.3 \pm 0.25 \times 10^{4}$ \\
17 & $1.5 \pm 0.20 \times 10^{2}$ & $3.0 \pm 0.0 \times 10^{2}$ & $3.2 \pm 0.25 \times 10^{4}$ \\
18 & $0.7 \pm 0.0 \times 10^{2}$ & $\mathrm{NF}$ & $9.2 \pm 0.20 \times 10^{2}$ \\
19 & $2.0 \pm 0.25 \times 10^{2}$ & $2.2 \pm 0.25 \times 10^{3}$ & $4.3 \pm 0.30 \times 10^{5}$ \\
20 & $\mathrm{NF}$ & $\mathrm{NF}$ & $6.2 \pm 0.20 \times 10^{2}$ \\
21 & $2.1 \pm 0.25 \times 10^{2}$ & $1.7 \pm 0.20 \times 10^{3}$ & $6.7 \pm 0.30 \times 10^{5}$ \\
22 & $1.0 \pm 0.20 \times 10^{2}$ & $0.7 \pm 0.0 \times 10^{2}$ & $1.7 \pm 0.25 \times 10^{4}$ \\
23 & $1.8 \pm 0.20 \times 10^{2}$ & $0.9 \pm 0.0 \times 10^{2}$ & $3.8 \pm 0.30 \times 10^{4}$ \\
24 & $\mathrm{NF}$ & $\mathrm{NF}$ & $2.3 \pm 0.20 \times 10^{2}$ \\
\hline & & &
\end{tabular}

${ }^{a} \mathrm{NF}=$ Not found.

highest intensity $\left(2.1 \pm 0.25 \times 10^{2} \mathrm{cfu} / \mathrm{g}\right)$ and the lowest level $\left(0.5 \pm 0.0 \times 10^{2} \mathrm{cfu} / \mathrm{g}\right)$ of SS were found in sample 21 and 7 respectively. The SS was identified in 14 out of total 24 samples (Table 3). As the marketed shrimp either frozen or fresh from Dhaka city directly brought from the shrimp farms, so the shrimp might contain SS isolates in Bangladesh ${ }^{(20)}$. 
The SS in aquaculture shrimp products mainly instigates from the environment rather than from poor standards of hygiene and sanitation. But sometimes, occurrence of these bacteria in shrimp may have happened due to external contamination(21). Cooking of shrimps prior to consumption causes negligible health risks to the consumers for cross contamination in the kitchens. Besides, faecal coliform are present highly in diarrhoeal stools of infected persons. So, the unwashed hands of infected food handlers forgetting to wash hands with soap after using the bathroom, may also contaminate food(18).

Among the 24 samples, 11 were found containing Vibrio spp. The highest load was found in sample $19\left(2.2 \pm 0.25 \times 10^{3} \mathrm{cfu} / \mathrm{g}\right)$ and the lowest density was $2.2 \pm 0.25 \times 10^{3} \mathrm{cfu} / \mathrm{g}$ in sample 10 (Table 3). It is very remarkable to find Vibrio spp. in frozen samples because Vibrio normally cannot survive in the frozen condition due to the absence of moisture(22). The probable reasons for survival of Vibrio spp. in frozen shrimp samples are the inadequate freezing condition and the presence of moisture during freezing.

There were considerable numbers of Staphylococcus spp. found in almost all samples experimented (Table 3). The highest load of Stephylococcus spp. was $6.7 \pm 0.30 \times 10^{5} \mathrm{cfu} / \mathrm{g}$ and the lowest was $2.1 \pm 0.25 \times 10^{2} \mathrm{cfu} / \mathrm{g}$ in samples 21 and 3, respectively (Table 3). This result indicates that shrimp specially the frozen sample may be contaminated with Staphylococcus via infected food handlers or from the environment. More often the contamination is from an infected individual with an infection on hands or with a cold or sore throat. In contrast, rapid growth and toxin production can take place in shrimp if recontamination with Staphylococcus occurs ${ }^{(14)}$.

Table 4. Sensitivity of E. coli, Salmonella-Shigella (SS) and Staphylococcus isolets to different antibacterial drugs.

\begin{tabular}{llll}
\hline Isolated strains & Resistant & Intermediate & Sensitive \\
\hline E. coli-1 & P, AMP, E, AML & PG, CN & C, K, S, TE \\
E. coli-2 & P, B, E, PG & AMP, TE & K, CN, S, AML \\
E. coli-3 & E, PG, B, P & AMP, TE & K, C, CN, S \\
E. coli-4 & P, B, PG, E & C, CN, AML & K, S, TE \\
SS-1 & E, PG, CN, TE, S, P & AMP & K, S, B \\
SS-2 & P, S, CN & AMP, AML & PG, TE, K, C, B \\
SS-3 & P, PG, B, TE & Nil & AMP, K, C, CN, AML \\
SS-4 & AML, PG, P, B, TE & AMP, E & CN, K, C \\
Staphylococcus-1 & AMP, AML, P, B, TE & Nil & C, S, PG, K, E \\
Staphylococcus-2 & AML, AMP, B, P & TE, K, E & S, K, PG \\
\hline
\end{tabular}

Antibiotic sensitivity pattern of E. coli, Salmonella-Shigella and Staphylococcus isolates are shown in Table 4. All of 10 isolates (four from each E. coli and Salmonella-Shigella and two of Staphylococcus spp.) were resistant against PG in the sensitivity test. Among the four isolates of E. coli, three were resistant to PG, B and E. Salmonella-Shigella (SS) isolates 
were also sensitive to B, whereas both Staphylococcus isolates were resistant to AML, AMP, B and one isolate was found resistant to TE (Table 4). This result indicates that the uncontrolled and irregular use of antibacterial agents are responsible for the occurrence of the antibiotic resistant trait among the pathogens and the majority of the drug resistant bacteria carry drug resistant $(\mathrm{R})$ factor ${ }^{(23)}$.

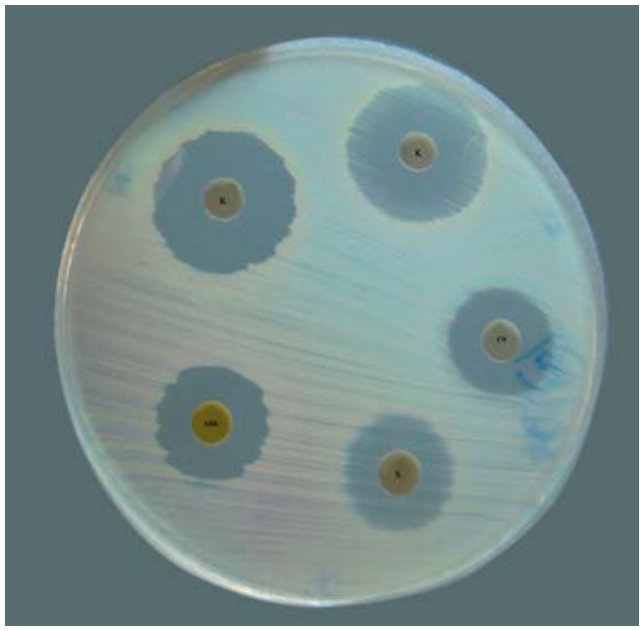

Fig. 1. Antibiotic susceptibility of E. coli in agar plate.

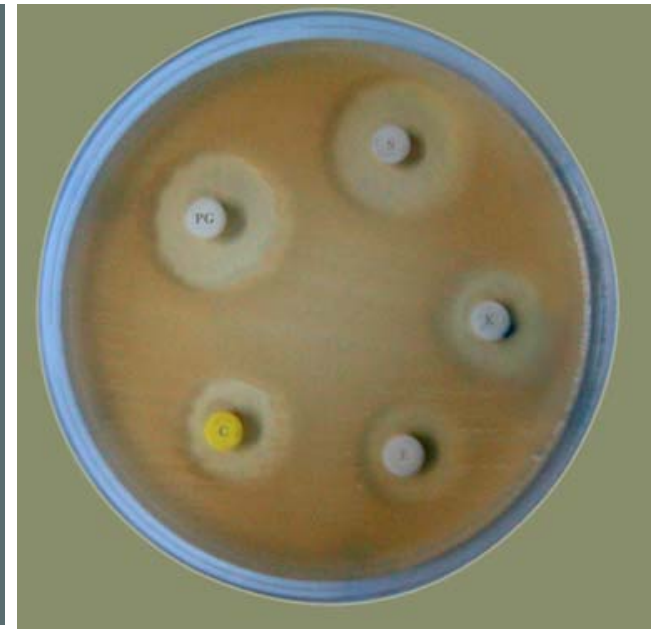

Fig. 2. Antibiotic susceptibility of Staphylococcus in nutrient agar plate.

The study provides information of the bacterial load in marketed shrimps. The samples from local markets were comparatively more contaminated with bacteria than those of departmental chain shops. The total bacteria and coliform count were found higher which indicate the unhygienic condition of the processing and marketing area.

Moreover, the products are stored for relatively long period in fluctuated power supply until sold and sometimes storage condition cannot be ensured properly due to handling disruption. So, the main reasons for infecting the local marketed shrimps might be rough handling and sorting or lack of sanitation. For frozen shrimps, fluctuation of storage temperature due to power interruption might be the major reason. Overall, the sub-tropical environment might also be the crucial reason for bacterial contamination in both market conditions. These results suggested that bacterial load of shrimps sold in local markets are of special concern. The retailers and handlers could take proper training on these aspects to avoid the health risks.

\section{Acknowledgements}

This study was conducted with National Science, Information and Communication Technology (NSICT) Fellowship from Ministry of Science and ICT, Government of Bangladesh under Research and Development Program is acknowledged gratefully. The 
authors also duly acknowledge about the supports provided by both Department of Fisheries and Department of Microbiology, University of Dhaka.

\section{References}

1. Clarence SY, CN Obinna and NC Shalom 2009. Assessment of Bacteriological Quality of Ready to eat Food in Benin City Metropolis, Nigeria. Afr. J. Microb. Res. 3(6): 390-395.

2. FAO/WHO Codex Alimentarius Commission 2000. Recommended Codes of Practice: Shrimps/Prawns (CAC/RCP 17-1978); Quick Frozen Shrimps/Prawns (Rev. 1-1995).

3. Edema MO, AM Omemu and MO Bankole 2005. Microbiological Safety and Quality of Readyto-eat Foods in Nigeria. 26pp. University of Agriculture, Abeokuta.

4. Phyllis E 2007. Food Safety: New Perspectives. ASM Press. Virginia, USA. p. 414.

5. Mobin SMA, MBR Chowdhury, MS Islam and MN Uddin 2001. Status of bacterial flora in the intestine of two freshwater fish. Bangladesh J. Life Sci. 13(1\&2): 149-155.

6. WHO (World Health Organization) 2002. Foodborne Disease, Emerging. Fact Sheet No. 124. http://www.who.int/mediacentre/factsheets/fs124/en/. Accessed on August 25, 2010.

7. Shafi M and MMA Quddus 2004. Bangladesh Matsho Shampad (Fisheries of Bangladesh). 2nd edition. Kabir Publications, Dhaka. pp. 323-325.

8. ICMSF (International Commission on the Microbiological Specification of Foods Microorganisms in food) 1998. Sampling for Microbiological Analysis: Principles and Specific Applications. Vol. 2. p. 142. University of Toronto Press, Toronto, Canada.

9. Bacteriological Analytical Manual 2005. USFDA for detection, enumeration and identification of individual organisms. Website: http://www.foodinfonet.com/publication/fdaBAM. html. Accessed on April 17, 2010.

10. American Society of Microbiology 1981. Manual for General Bacteriology. Website: http://ourfood.com/General bacteriology.html. Accessed on April 15, 2010.

11. Cappuccino JG and N Sherman 1990. Microbiology : A Laboratory Manual. 4th Edition. pp. 137183.

12. Banik RCK and NM Humayun 1999. Information on Fish of Bangladesh. Official Report, Department of Fisheries, MoFL, GoB, Dhaka.

13. ICMSF (International Commission on Microbial Specification for Foods) 1986. Microorganisms in foods. In: Application of the Hazard Analysis Critical Control Point (HACCP) System to Ensure Microbiological Safety and Quality. p. 42. Blackwell Scientific Publications.

14. Hatha MAA, TK Maqbool and S Kumar 2003. Microbial quality of shrimp products of export trade produced from aquacultured shrimp. Int. J. Food Microbiol. 5(2): 82, 213-221.

15. Wahab MA, A Bergheim and B Braaten 2003. Water quality and partial mass budget in extensive shrimp ponds in Bangladesh. Science Direct (Internet ed). pp. 218, 413-423.

16. Leita o MFF and DPA Rios 2000. Microbiological and chemical changes in rreshwater prawn stored under refrigeration. Braz. J. Microbiol. 13(3): 3-7.

17. Boyd CE 1990. Water quality in ponds for aquaculture. p. 480. Birmingham Publishing Co., Alabama, USA.

18. Center for Disease Control and Prevention, FAQ. Escherichia coli. Website: http ://www.cdc. gov/ncidod/dbmd/diseaseinfo/ escherichiacoli_g.html. Accessed on May 10, 2010. 
19. FAO Fisheries Department 1997. Review of the state of world aquaculture. FAO fisheries circular No. 886 FIRI/ C 886 (Rev. 1). Website: http: //www.fao.org/fi/. Accessed on May 18, 2010.

20. Reilly PJA, DR Twiddy and RS Fuchs 1992. Review of the occurrence of salmonella in cultured tropical shrimp. FAO Fish. Circ. No. 851. FAO, Rome, Italy.

21. Huss HH 1994. Assurance of seafood quality. FAO Fisheries Technical Paper. pp. 334. 94, 97, 169. Food and Agriculture Organization, Rome.

22. Jay JM 1996. Modern food microbiology. 4th edition. Maryland: Aspen Publishers Inc. pp. 583-585.

23. Keys A, JT Anderson and F Grande 1986. Serum cholesterol response to changes in the diet. Metabolism. 14(7): 776-787.

(Manuscript received on 24 July, 2011; revised on 17 November, 2011) 